\title{
Changes in corneal biomechanics following different keratoplasty techniques
}

This article was published in the following Dove Press journal:

Clinical Ophthalmology

8 June 2011

Number of times this article has been viewed

\section{Mohamed Hosny \\ Mohamed Abdel Moneim \\ Hassaballa \\ Ahmed Shalaby \\ Ophthalmology Department, Faculty of Medicine, Cairo University, Cairo, Egypt}

Purpose: To evaluate corneal biomechanics with the Ocular Response Analyzer (ORA; Reichert Ophthalmic Instruments, Depew, NY) after penetrating keratoplasty (PK) and deep anterior lamellar keratoplasty (DALK).

Subjects and methods: Sixty-three eyes of 63 patients were included in this prospective comparative study. Patients were divided into 3 groups: the first included 21 eyes of normal subjects (control group); the second included 21 eyes with PK; the third included 21 eyes with DALK. ORA was performed 2 months postoperatively for all patients.

Results: Both mean corneal hysteresis $(\mathrm{CH})$ and mean corneal resistance factor $(\mathrm{CRF})$ were significantly lower in the PK group than both the DALK group and matched controls. No statistically significant difference was found between mean $\mathrm{CH}$ and mean CRF between the DALK group and matched controls

Conclusion: Corneas after PK have weaker biomechanical properties than normal corneas. DALK preserves the biomechanical strength of the corneas to almost normal values.

Keywords: hysteresis, keratoplasty, keratoconus

\section{Introduction}

Corneal biomechanics have been studied over recent years. Previously, assessment of the biomechanical properties of the cornea was only possible with theoretical and laboratory models. ${ }^{1}$ The Ocular Response Analyzer (ORA; Reichert Ophthalmic Instruments, Depew, NY) is the first simple device able to provide an in vivo dynamic assessment of the biomechanical properties of the cornea. ${ }^{2}$

The ORA functions by emitting an air jet to deform the cornea. The air-jet pressure is steadily increased until the first force-in applanation event is reached. This applanation event is the trigger to switch off the air jet after some further increase in air pressure. After reaching the pressure peak, the air pressure slowly reduces until it is completely removed. The instrument makes 2 measurements of the corneal response to the air pressure pulse: the force necessary to flatten the cornea as the air pressure rises and the force at which the cornea flattens again as the air pressure falls. ${ }^{2}$ It has been found that the second, force-out applanation occurs at a lower pressure than the first, force-in applanation, and this effect has been attributed to the dampening effects of the cornea. The difference between these two pressures has been termed corneal hysteresis $(\mathrm{CH})$ (Figure 1). Hysteresis is a measure of the energy absorption during the "loading-unloading, stress-strain cycle of viscoelastic materials." $\mathrm{CH}$ is believed to be a reflection of the damping properties of the cornea ${ }^{4}$ and forms the basis of a derived parameter, the corneal resistance factor $(\mathrm{CRF}) .^{5}$
Correspondence: Mohamed Hosny 84 Shehab Street, Mohandeseen, Giza, I24I I, Egypt

Tel +20100007675

Fax +20233372117

Email mohamedhosny@mac.com 


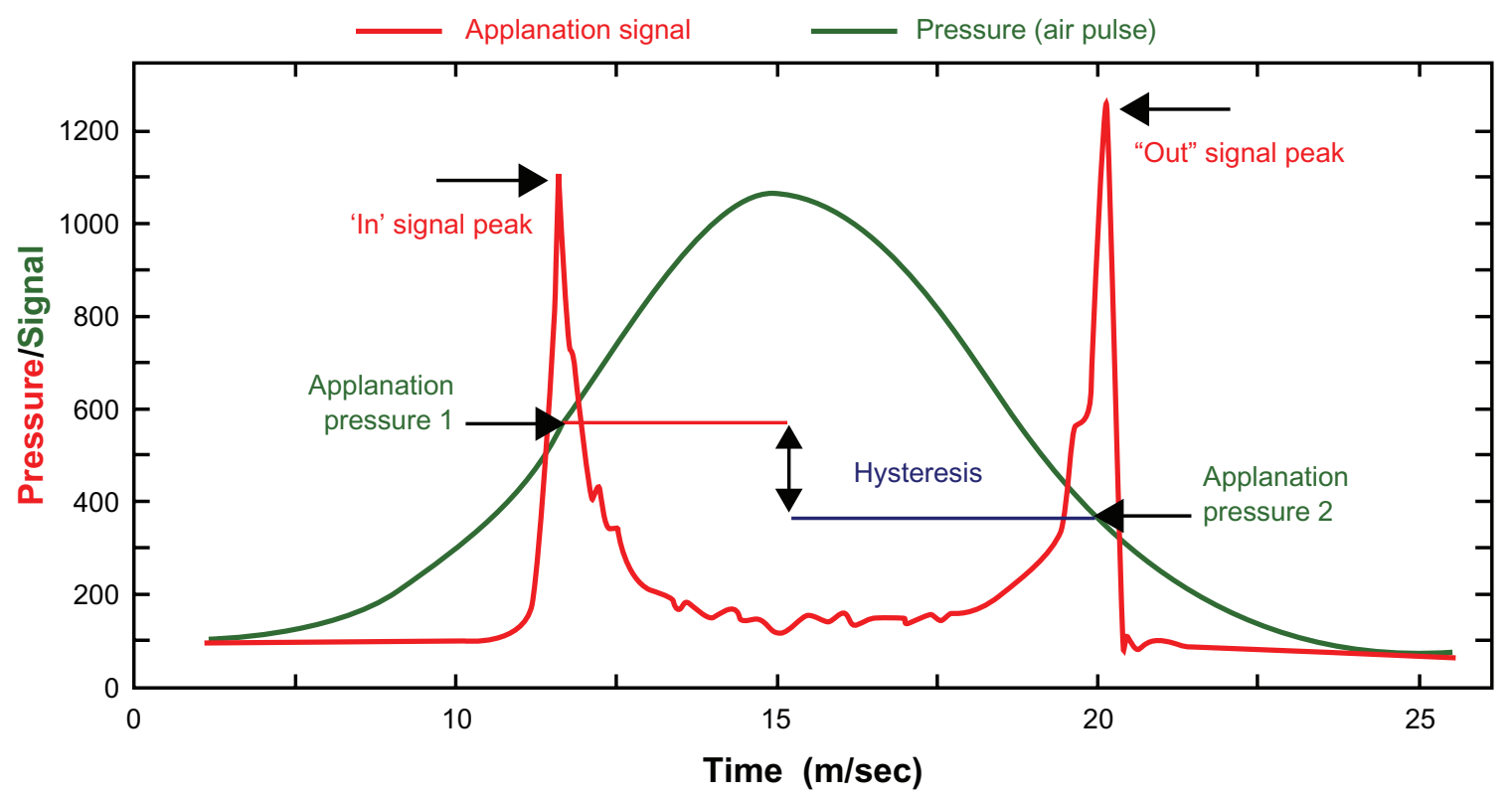

Figure I Corneal hysteresis.

In 1936, Castroviejo did a first transplantation in an advanced case of keratoconus, achieving significant improvement in the patient's vision. ${ }^{6}$ At present, and even though penetrating keratoplasty (PK) continues to be the standard corneal transplant technique, deep anterior lamellar keratoplasty (DALK) is attaining greater relevance. One of the reasons for the increased popularity of this technique is the enhanced surgical safety afforded by the improved integrity of the ocular structure during the intervention, which is an extraocular procedure. Moreover there is no chance of endothelial rejection in lamellar keratoplasty due to the recipient's own endothelium being retained. However, lamellar keratoplasty cannot be applied in cases of total involvement of the corneal thickness. ${ }^{?}$

The aim of this study was to evaluate the corneal biomechanics by ORA after PK and DALK.

\section{Subjects and methods}

Sixty-three eyes of 63 patients were included in this prospective comparative study. Patients were divided into 3 groups: the first included 21 eyes of normal subjects (control group); the second included 21 eyes with PK; the third included 21 eyes with DALK.

The cases were matched in age to avoid the natural crosslinking that occurs in the cornea with age. The mean ages (years) were: control group $24.3 \pm 4.0$, PK group $24.5 \pm 3.8$, and DALK group $24.52 \pm 4.4$. The cases were matched in indications to avoid gross variation in the biomechanical properties of the recipient corneal bed. The cases with PK included: 11 cases had keratoconus with Descemet membrane (DM) scars; 5 cases had full thickness corneal opacities; and 5 cases were keratoconus that had unplanned PK after DM perforation during DALK. The cases with DALK included: 12 cases had keratoconus; 5 cases had post-LASIK ectasia; and 4 cases had anterior stromal opacities due to recurrent herpetic keratitis. ORA was performed 2 months postoperatively for all patients. Each patient's ORA measurement is a mean of 4 consecutive air-puff applanations. Irreproducible ORA measures were excluded from the study. At the same visit central corneal thickness (CCT) was measured by an ultrasonic pachymeter.

\section{DALK technique of (big bubble technique)}

The technique involved a partial thickness trephination with the Hanna suction trephine (Moria S.A., Antony, France), set at approximately $60 \%$ of the peripheral stromal thickness, taking care to encompass the entire stromal lesion. A 30-gauge needle attached to an air-filled syringe, bevel down, was inserted and advanced approximately $2-3 \mathrm{~mm}$ into the remaining posterior stroma, at a plane almost parallel to the corneal surface, so as not to perforate DM. Forceful air injection into the posterior stroma results in a "big-bubble" with separation of DM from the posterior stroma. Anterior lamellar dissection of the anterior stroma was then performed with a Mini-Crescent blade (1.25 mm, Sharpoint, UK) and a conventional crescent blade ( $2.25 \mathrm{~mm}$, BD Visitec, UK), to gain access to the posterior stromal surface. The bubble was 
then released and the posterior stroma was carefully removed with the use of blunt-tipped corneal scissors. A partial thickness donor cornea was sutured into place after removal of DM. The trephination diameter in the receiving cornea was in the range of $7.5-7.75 \mathrm{~mm}$, with a donor trephination $0.25 \mathrm{~mm}$ larger.

\section{PK technique}

The donor cornea was trephinated with a punch and the receiving cornea with a suction trephine. As in the DALK group, the trephination diameter in the receiving cornea was in the range of $7.5-7.75 \mathrm{~mm}$, with a donor trephination $0.25 \mathrm{~mm}$ larger. The chamber was then filled with high density viscoelastic material. First interrupted 4-stitch sutures were made and then completed later with a further 16 stitches or a nylon 10/0 continuous suture. The interventions were made by one surgeon (HM).

Postoperative regimen was the same in both PK and DALK groups. It was as follows: patients were given topical postoperative combined tobramycin $0.3 \%$ and dexamethasone $0.1 \%$ (Tobradex ${ }^{\circledR}$, Alcon Hünenberg, Swritzerland) which was tapered gradually. All patients were examined at postoperative 1 day; 1,2 , and 4 weeks; and 2 months.

Data were statistically described in terms of range, mean, and standard deviation (SD), Correlation between various variables was done using independent samples test. $P$ values $<0.05$ were considered statistically significant. All statistical calculations were done using computer programs Microsoft Excel 2007 (Microsoft Corporation, NY) and SPSS (Statistical Package for the Social Science; SPSS Inc, Chicago, IL) version 15 for Microsoft Windows.

\section{Results}

\section{Corneal hysteresis (Figure 2)}

Mean CH was $10.86 \mathrm{~mm} \mathrm{Hg} \pm 1.36$ (range $8.3-13 \mathrm{~mm} \mathrm{Hg}$ ) in the control group; $9.57 \mathrm{~mm} \mathrm{Hg} \pm 0.33$ (range 7-12 $\mathrm{mm} \mathrm{Hg}$ ) in the PK group; and $10.87 \mathrm{~mm} \mathrm{Hg} \pm 1.39$ (range $8-13 \mathrm{~mm} \mathrm{Hg}$ ) in the DALK group. There was no statistically significant difference between mean $\mathrm{CH}$ in the DALK group and the matched controls. Mean $\mathrm{CH}$ in the $\mathrm{PK}$ group was significantly lower than in the other 2 groups $(P=0.003)$.

\section{Corneal resistance factor (Figure 3)}

Mean CRF was $11.16 \mathrm{~mm} \mathrm{Hg} \pm 1.5$ (range 8.5-13.5) in the control group; $9.59 \mathrm{~mm} \mathrm{Hg} \pm 1.5$ (range 7.5-12.5) in the PK group; and $11.25 \mathrm{~mm} \mathrm{Hg} \pm 1.46$ (range 8.5-13.5) (Figure 3) in the DALK group. There was no statistically significant difference between mean CRF in the DALK group and the

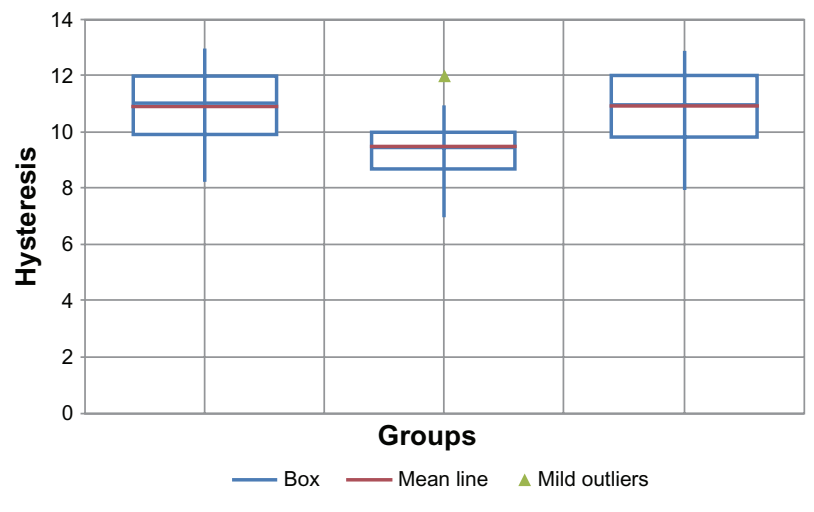

Figure 2 Corneal hysteresis in the 3 groups.

matched controls. Mean CRF in the PK group was significantly lower than in the other 2 groups $(P<0.01)$.

Within each group, there was no statistically significant difference between mean $\mathrm{CH}$ and mean $\mathrm{CRF}$, ie, no $\mathrm{CH} / \mathrm{CRF}$ dissociation.

Mean CCT was $549.24 \mu \mathrm{m} \pm 18.26$ in the control group; $561.67 \mu \mathrm{m} \pm 24.33$ in the PK group; and $569.31 \mu \mathrm{m} \pm 32.39$ In the DALK group. The difference between the 3 groups was not statistically significant.

Mean intraocular pressure (IOP) was $17.66 \mathrm{~mm} \mathrm{Hg} \pm 2.36$ in the control group; $18.52 \mathrm{~mm} \mathrm{Hg} \pm 1.83$ in the PK group; and $16.47 \mathrm{~mm} \mathrm{Hg} \pm 1.89$ in the DALK group. The difference between the 3 groups was not statistically significant.

\section{Discussion}

The influence of corneal biomechanics on the results of various corneal surgical procedures is well recognized. Studying the change in corneal biomechanics caused by different procedures can lead to better understanding and fine tuning of the results.

In this study, both mean $\mathrm{CH}$ and mean $\mathrm{CRF}$ were significantly lower in the PK group than both the DALK group and the matched controls. No statistically significant difference was found between mean $\mathrm{CH}$ and mean CRF between the

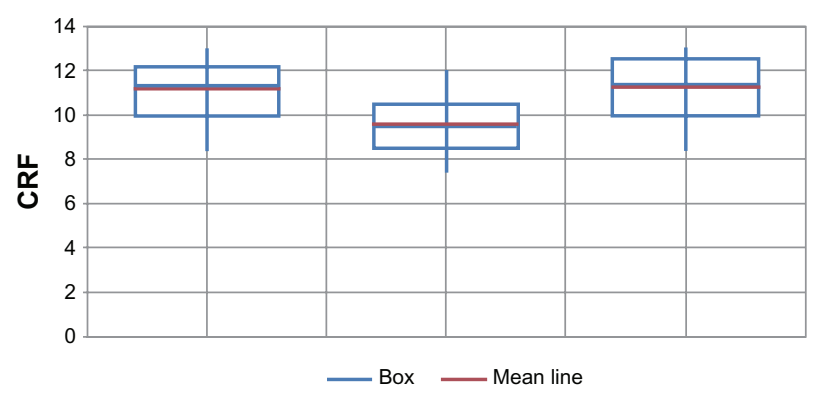

Figure 3 Corneal resistance factors (CRF) in the 3 groups. 
DALK group and the matched controls. To our knowledge, no study on the effect of different keratoplasty techniques on $\mathrm{CH}$ and $\mathrm{CRF}$ has been reported.

In normal conditions $\mathrm{CH}$ and $\mathrm{CRF}$ have mostly similar values and are correlated; unless there are unusually high or low values in either the CCT or IOP, $\mathrm{CH} / \mathrm{CRF}$ dissociation can occur. In the patient series reported in this study, none of the groups exhibited $\mathrm{CH} / \mathrm{CRF}$ dissociation, ie, $\mathrm{CH}$ and $\mathrm{CRF}$ were correlated and values were close. In contrast, Touboul et $\mathrm{al}^{8}$ reported $\mathrm{CH} / \mathrm{CRF}$ dissociation in subclinical keratoconus patients, keratoconus patients, and LASIK patients and they assumed that this dissociation is sensitive for screening for weak corneas. But in his series of patients, the corneas that were assessed were affected by keratoconus or ectasia, which explains the dissociation between the $\mathrm{CH}$ and the $\mathrm{CRF}$ since the CRF is basically the $\mathrm{CH}$ corrected to both the CCT and the IOP. In cases with keratoconus, the CCT is much lower than normal, which may result in lower CRF values than normal. In our study, though, the patients had already undergone corneal transplantation, so the corneas assessed were transplanted corneas with normal CCT.

In the control patients reported in our study, mean $\mathrm{CH}$ was $10.86 \mathrm{~mm} \mathrm{Hg} \pm 1.36$. Mangouritsas et $\mathrm{al}^{9}$ reported a mean $\mathrm{CH}$ of $10.97 \pm 1.59$; Touboul et $\mathrm{al}^{8}$ reported a mean $\mathrm{CH}$ 9.3; Kamiya et $\mathrm{al}^{10}$ reported a mean $\mathrm{CH}$ of $10.2 \pm 1.3$; Lim et $\mathrm{al}^{11}$ reported a mean $\mathrm{CH} 11.78 \pm 1.55$ in Singaporean children; and Shah et $\mathrm{al}^{5}$ reported a mean $\mathrm{CH}$ of $10.7 \pm 2$. In another study performed on 281 Egyptians' eyes, mean $\mathrm{CH}$ was $9.78 \pm 1.63 .{ }^{12}$

In conclusion, it seems that corneas after PK have weaker biomechanical properties than normal corneas. DALK preserves the biomechanical strength of the corneas to almost normal values. We believe that the continuity of the Descemet membrane in both the DALK group and the control group acts as a shell foundation for the rest of the corneal stroma which rests above it, and hence the $\mathrm{CH}$ is similar in these 2 groups. As for the PKP group, the incised Descemet membrane all around the border of the full thickness graft and the separation of the central disc of this membrane from the rest of it that is in the host bed gravely affects its ability to form a continous strong scaffold foundation for the overlying stroma, and so the $\mathrm{CH}$ is decreased. We believe that the Descemet membrane is a thin $(10-12 \mu \mathrm{m})$ but strong layer, as evidenced by the formation of a descematocele in deep corneal ulcerations that resists perforation of the globe, sometimes for days when all the rest of the stroma has melted. In this study it seems that the uninterrupted host DM acted as a shell foundation that mechanically supported the overlying corneal graft and kept its biomechanics near normal values.

\section{Disclosure}

The authors report no conflicts of interest in relation to this work.

\section{References}

1. Guirao A. Theoretical elastic response of the cornea to refractive surgery: risk factors for keratectasia. J Refract Surg. 2005;21:176-185.

2. Luce DA. Determining in vivo biomechanical properties of the cornea with an ocular response analyzer. $J$ Cataract Refract Surg. 2005; 31:156-162.

3. Kotecha A, El Sheikh A, Robetrs C, et al. Corneal thickness and age related biomechanical properties of the cornea measured with ocular response analyzer. Invest Ophthalmol Vis Sci. 2006;47:5337-5347.

4. Kotecha A. What biomechanical properties of the cornea are relevant for the clinician? Surv Ophthalmol. 2007;52:S109-S114.

5. Shah S, Laiquzzaman M, Cunliffe I, Mantry S. The use of the Reichert ocular response analyser to establish the relationship between ocular hysteresis, corneal resistance factor and central corneal thickness in normal eyes. Cont Lens Anterior Eye. 2006;29:257-262.

6. Castroviejo R. Keratoplasty for the Treatment of Keratoconus. Trans Am Ophthalmol Soc. 1948;46:127-153.

7. Lopez S, Etxebbaria J, Acera A, et al. Protected penetrating keratoplasty: Surgical technique and endothelial response. Arch Soc Esp Oftalmol. 2008;83:231-236.

8. Touboul DA, Roberts CA, Karautret JA, et al. Correlation between corneal hysteresis, intraocular pressure and corneal central pachymetry. $J$ Cataract Refract Surg. 2008;34:616-622.

9. Mangouritsas G, Morphis G, Mourtzoukos S, Feretis E. Association between corneal hysteresis and central corneal thickness in glaucomatous and non-glaucomatous eyes. Acta Ophthalmol. 2009;87:901-905.

10. Kamiya K, Hagishima M, Fujimura F, Shimizu K. Factors affecting corneal hysteresis in normal eyes. Graefes Arch Clin Exp Ophthalmol. 2008;246:1491-1494.

11. Lim L, Gazzard G, Chan Y, et al. Cornea biomechanical characteristics and their correlates with refractive error in Singaporean children. Invest Ophthalmol Vis Sci. 2008;49:3852-3857.

12. Hassaballa M. Correlation between corneal hysteresis and central corneal thickness. J Cataract and Cornea. 2011;17:10-14.
Clinical Ophthalmology

\section{Publish your work in this journal}

Clinical Ophthalmology is an international, peer-reviewed journal covering all subspecialties within ophthalmology. Key topics include: Optometry; Visual science; Pharmacology and drug therapy in eye diseases; Basic Sciences; Primary and Secondary eye care; Patient Safety and Quality of Care Improvements. This journal is indexed on Submit your manuscript here: http://www.dovepress.com/clinical-ophthalmology-journal

\section{Dovepress}

PubMed Central and CAS, and is the official journal of The Society of Clinical Ophthalmology (SCO). The manuscript management system is completely online and includes a very quick and fair peer-review system, which is all easy to use. Visit http://www.dovepress.com/ testimonials.php to read real quotes from published authors. 